\title{
Trees, Knots, and Outriggers: Environmental Knowledge in the Northeast Kula Ring. By Frederick H. Damon. 2017. Berghahn, New York. 375 pp.
}

\author{
Patricia K. Townsend ${ }^{1^{*}}$ \\ ${ }^{1}$ Department of Anthropology, University at Buffalo, Buffalo, NY, USA \\ *pkt@buffalo.edu
}

Received November 27, 2017

Accepted December 10, 2017

OPEN ӘACCESS

DOI 10.14237/ebl.9.2.2018.1177

Copyright (C) 2018 by the author(s); licensee Society of Ethnobiology. This is an open-access article distributed under the terms of the Creative Commons Attribution-NonCommercial 4.0 International Public License (https://creativecommons.org/licenses/by-nc/4.0), which permits non-commercial use, distribution, and reproduction in any medium, provided the original author and source are credited.

In the early 1990s, mid-career social anthropologist Frederick Damon re-invented himself as an environmental anthropologist for a series of visits to his original field site on Muyuw (Woodlark) Island, Papua New Guinea, where he had made several previous trips to study kinship and exchange in the 1970s and 1980s. At the same time, he broadened the scope of his work from the Kula Ring region in Milne Bay Province off the east coast of Papua New Guinea to include China, as he worked toward encompassing a world-system linked by Austronesian-speaking seafarers. This bold double move is documented in the book under review.

Although Damon does not use the term landscape ecology (preferring the term historical ecology), we might categorize the first two-thirds of the book with either term. Muyuw is a raised coral island with a volcanic core. Its forests are heavily modified by agriculture and now also by logging and mining exploration. Chapter one deals in detail with the three types of fallow period distinguished in the Muyuw language and the trees related to garden planning. It reports Muyuw planting of the gwed tree (Rhus taitensis) to enhance or "sweeten" the soil of gardens. Extensive efforts to determine how gwed improved the yield of the yams (Dioscorea esculenta) planted adjacent to it were inconclusive, though it seemed most likely that it addressed potassium deficiency.

Chapter two deals with Muyuw classification and categorization of trees in general. Chapter three describes the use of trees to name and characterize places or ecological zones. In this chapter Damon deals with the sago orchards (Metroxylon sagu) and their relationship to meadows: the dense thickets of grass and ferns that are the only un-forested areas of the island, with leached soils that are highly acidic and high in aluminum. Sago starch is an important food in the lean seasons for farming. Chapter four centers on another set of trees: the several species of Calophyllum. Six types are locally distinguished-each with different properties and uses as well as growing conditions-challenging systematists at the herbaria to which Damon submitted specimens and resulting in the description of new species by Peter Stevens.

Muyuw attention to several species of Calophyllum, particularly for the properties of the grain of their wood, leads into the final third of the book, which deals with the use of flora in the construction of seagoing outrigger canoes. More than once, I found myself wishing that the book had been split into two books at this point: one book on trees and a second on boats, edited to include some discussion of the materials used in their construction. I suspect that most ethnobiologists are unlikely to persist through the discussion of tying knots, weaving sails, and on into the detailed structure of boats. A sailor, skipping those lengthy chapters on trees, could not fully appreciate the choice of boat-building materials. These decisions are of life-threatening significance as the wrong materials may cause a mast or rudder to "explode" in high winds and heavy seas. The amount of detail amassed after a few chapters is beyond holding in a reader's memory, though an improved glossary and index would help. 
Chapter five is titled $V$ atul, vines. After listing the 44 vines collected or described, it deals primarily with the use of vines in tying, particularly in constructing boats, but also in making fishnets and string figures. Deep into his discussion of vines and knots in Muyuw, Damon tells the self-deprecating story of the slurs he suffered by tying two ends of a cord with sip vinay, the granny knot he usually makes, rather than with sip tawau, the square knot he needed to be taught during his fieldwork. Nowhere in the text or index are line drawings or English terms for these knots given. Not until the reader digs through photographs published online is any of this clear, and then perhaps only to readers who learned knots as a Scout. This anecdote epitomizes the challenges that make Trees, Knots, and Outriggers nearly unreadable, at least for scholars working outside the kula ring. The text is liberally sprinkled with vernacular terms that are rarely given an English gloss. There is no glossary, and the index is less helpful than it might be. Further, the text lacks diagrams of knots, boats, or trees, and the line drawings promised in the preface failed to appear with the photographs on the web site: https:// pages.shanti.virginia.edu/Trees Knots Outriggers/ table-of-contents/ (accessed November 27, 2017). Nevertheless, this reader persisted, determined to recognize instructive analogies with mainland Papua New Guinea ethnobotany.

The granny-knot anecdote hints at another feature of Damon's writing, which is the thorough recounting of his discovery process, both in the field and in his travels to meet other scholars at their home institutions and conferences. Those who have undertaken similar projects, even on a small scale, will appreciate Damon's discussion of the ethnobotanical discovery process, but it burdens the text with yet more complexity and might better have been discussed in a separate publication, as a memoir or case study on field methods.

Chapter six describes the internal structure of the anageg, the seagoing outrigger sailing canoe, even now being replaced by dinghy and outboard motor. Discussing the construction of mast, outrigger float, keel, strakes, ribs, rudder, and decorative carvings, Damon returns to the properties of trees that make them suitable or unsuitable for each part of the boat. Again, the scarcity of line drawings makes this difficult going for the landlubber.

As an ethnobiologist Damon sees himself as the mediator between two sets of experts on trees: the Pacific Islanders he revisits over a period of forty years, and the botanists in herbaria at Harvard and Lae who work with his voucher specimens. Disagreements among his teachers are recounted, illustrating the variability among individuals in the acquisition of traditional knowledge as well as ecological variability and cultural specialization throughout the northeast Kula Ring region from the Trobriands to Muyuw. This specialization enables people to thrive despite the challenges of multi-year variation in the El Niño Southern Oscillation.

This is rich data from long and wide-ranging fieldwork and deserving of more analysis and editing into more digestible form. Without that, it is likely to remain on the bookshelves of a small set of specialist libraries. 